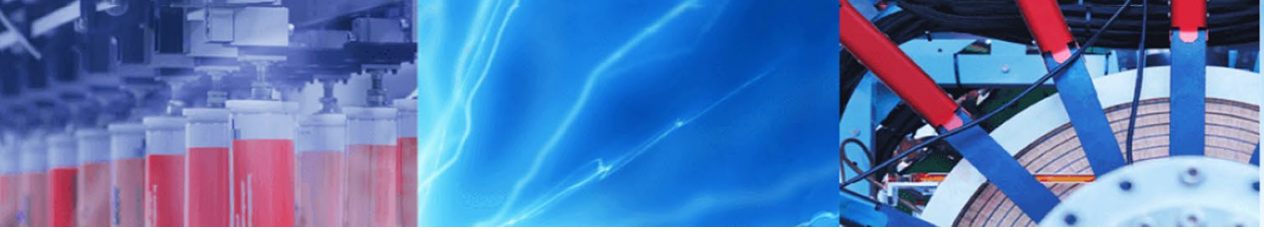

Research Article

\title{
Determination of kerosene as an adulterant in diesel through chromatography and high-resolution mass spectrometry
}

\author{
Bhanu Prasad Vempatapu ${ }^{1} \cdot$ Deependra Tripathi ${ }^{1} \cdot$ Jagdish Kumar ${ }^{1} \cdot$ Pankaj K. Kanaujia $^{1}$
}

(c) Springer Nature Switzerland AG 2019

\begin{abstract}
In India, adulteration of petroleum-based automotive fuels is a serious concern which has attracted the attention of media and regulators from time to time. Monitoring adulteration of automotive fuels is often challenging due to the similarity in the properties of adulterants with that of the fuel (gasoline or diesel). The present study investigates a typically prevalent case of Euro IV diesel fuel adulteration with low-value subsidized kerosene. Diesel samples contaminated with kerosene were analyzed for density, viscosity, atmospheric distillation, aniline point, total sulfur and cetane index to generate an initial assessment of the adulteration. In view of the inadequacy of these methods in identifying the diesel adulteration even with up to $40 \%$ kerosene, chromatographic [gas chromatography (GC) and high-performance liquid chromatography (HPLC)] and high-resolution mass spectrometric (HRMS) analysis were carried out to detect the fingerprint regions in samples. Total sulphur, aniline point and atmospheric distillation (recovery at $250{ }^{\circ} \mathrm{C}$ ) gives primary evidence for determining the presence of kerosene (adulterant) in diesel fuel. There was a considerable increase in the $n-C_{10}$ to $n-C_{12}$ and decrease in $n-C_{15}$ to $n-C_{20}$ hydrocarbons in the adulterated samples through GC. Similarly, the HRMS measurements showed a significant increase of alkylbenzenes concentration in the adulterated samples. A good correlation was observed between HPLC and HRMS results of saturates, mono, di, tri+-aromatics in adulterated diesel samples. The Student's $t$ test showed an excellent correlation between the values of different hydrocarbon groups in all the samples obtained with HPLC and HRMS analysis.
\end{abstract}

Keywords Diesel · Kerosene · Adulteration · Gas chromatography · High-performance liquid chromatography $\cdot$ Highresolution mass spectrometry

\section{Introduction}

Diesel is a high energy automotive fuel used predominantly in public transport and passenger cars besides being also used for running agricultural equipment and household appliances [1]. It has a higher heating value as compared to gasoline and offers a higher volumetric energy density. Diesel is combusted in a compressionignition engine where the fuel is atomized and sprayed into the hot compressed air. It has a boiling range of $180-370^{\circ} \mathrm{C}$ and contains $10-19$ carbon atoms in the form of paraffins, naphthenes, and aromatics in different proportions $[1,2]$. There are several processes (distillation, catalytic cracking, hydro-cracking etc.) through which diesel fuel is obtained from the crude oil [1]. The adulteration of automotive fuels is prevalent in the different parts of the developing world including India and has erupted as a result of dishonest profit-making practices, negligence on the part of regulators, limited resources for its verification and weak policies to curb it $[2,3]$. In the case of diesel, adulteration often leads to the non-conformance of its regulatory requirements, thereby implying degradation in its quality which eventually leads to the economic losses, increased tailpipe

$\triangle$ Pankaj K. Kanaujia, pankajkk@iip.res.in | ${ }^{1}$ Analytical Sciences Division, Indian Institute of Petroleum, Council of Scientific and Industrial Research, Haridwar Road, Dehradun, Uttarakhand 248005, India.

SN Applied Sciences (2019) 1:614 | https://doi.org/10.1007/s42452-019-0637-7

Received: 4 February 2019 / Accepted: 17 May 2019 / Published online: 21 May 2019 
emissions, deterioration of engine performance and wear of engine parts [2-5]. Fuel quality is one of the essential parameters of environmental assessment and a measure of public health, necessary for the developing economies. Due to the financial benefits arising from the taxation policy of the Government, automotive gasoline and diesel are often adulterated to maximize the profits $[2,6-9]$. The selection criteria for adulterant are based on its ready miscibility with the fuel, availability at cheaper rates and similarity in the physicochemical properties as compared to the unadulterated fuel. Largely, various petroleum-based products easily fulfil these requirements and hence preferred as adulterants to the automotive fuels $[2,10]$. In India, there has been an increased concern on this issue partially due to the lack of organized research in this area and dangerously rising air pollution levels [11-13].

Kerosene has merit for being used as an adulterant of automotive diesel due to the overlapping hydrocarbons (i.e., $\mathrm{C}_{6}-\mathrm{C}_{16}$ in kerosene and $\mathrm{C}_{10}-\mathrm{C}_{19}$ in diesel) and its availability at the lower price. In India, it is also sold at the subsidized price for economically weaker sections, and the roughly threefold difference exists between the costs of the subsidized and non-subsidized kerosene [2]. The subsidized kerosene is also termed public distribution system (PDS) kerosene which is known to possess higher levels of sulfur. As an adulterant to the diesel, it may lead to the formation of sulfuric acid which is one of the factors known to cause severe damage to the engine. The damages include sudden drops in the engine, difficulties in starting, increased fuel consumption and increased emissions of the particulates, $\mathrm{SO}_{x}$ and exhaust gases [14-17]. Other adulterants to automotive diesel fuel are biodiesels, vegetable oils (soybean, corn, cotton, palm oil, etc.) and residual oils (automotive lubricant oil and waste cooking/ frying oil) $[2,18,19]$.

Verification analysis intended for the determination of adulteration in diesel is challenging and requires analysis with different analytical techniques [2]. Bharat Stage (BS) IV is equivalent to Euro IV emission standard and the regulatory specification of BSIV complied diesel fuel in India is as per IS 1460 . Diesel adulteration is typically monitored through the measurement of various physicochemical properties such as density, kinematic viscosity, boiling range characteristics, flash point, etc. $[2,20]$. There are reports where atmospheric distillation $[2,20,21]$ and Kinematic viscosity have been used to provide evidence of the adulteration [22]. Measurement of aniline point strongly signify the nature of fuel regarding its aromatic or aliphatic nature since the aromatics exhibit lower values than saturates while naphthenes and olefins show values between these two extremes $[1,21]$. There are limited reports on the diesel adulteration measurement with other analytical methods as chromatography and spectroscopy although some have been reported through physicochemical methods only $[22,23]$.

The modern tools of chemical analysis ensure unambiguous identification of the target species at molecular levels. It has necessitated the need for the development of reliable analytical methods for precise determination of diesel adulteration even at the trivial levels. In this reference, it shall be noted that the analysis of gasoline is considered easier than other heavier products (middle distillates onwards). It is due to the less complex hydrocarbon framework which is easily and unambiguously determined at the component level with GC-based standard test method (ASTM D6730). GC, however, is considered inadequate for middle distillates and above due to the limitation in resolving the individual compounds except for n-paraffins [24]. Only a few studies have been reported for diesel adulteration monitoring and they have differentiated kerosene in diesel utilizing nuclear magnetic resonance (NMR), GC coupled to field ionization mass spectrometry (GC-FIMS), easy ambient sonic-spray ionization mass spectrometry (EASI-MS) and synchronous fluorescence scan (SFS) [16, 25-27]. A low-resolution mass spectrometry based method is often recommended for the determination of hydrocarbon types in middle distillates (ASTM D2425). The pre-requisite to this method is the tedious sample preparation to segregate saturates and aromatics before the analysis (ASTM D2549). An alternative to ASTM D2425 is the high-resolution mass spectrometry (HRMS) based HC22 method which calculates the concentrations of 22 hydrocarbon types in the middle distillates without any sample preparation [28]. A comprehensive overview of the common adulteration monitoring practices for petroleum fuels has been reviewed [2]. Based on the observations, it is necessary to explore the scope for the development of efficient analytical methods based on chromatography and spectroscopy with an opportunity to investigate the nature and levels of adulterants in the automotive diesel fuel.

The present investigation is aimed at verifying the presence of varying levels of PDS kerosene as an adulterant to the BSIV diesel. A detailed analytical protocol was adopted to achieve this with the help of physicochemical, chromatographic (GC, HPLC) and mass spectrometric approaches. One of the objectives of this work is to highlight the limitations of the physicochemical methods test methods in determining the presence of kerosene in automotive diesel fuel. The role of HRMS is significantly presented in the presented case where details about the hydrocarbon types of samples were correctly established and complemented with HPLC-based IP391/ASTM D6591. In addition, the authors have presented a correlation between different analytical methods acting as a basis to predict the 
adulteration of diesel fuel. To the best of our knowledge, the present study with its adopted methodology is original and not reported previously.

\section{Experimental details}

\subsection{Chemicals and materials}

The Bharat Stage IV (BSIV) diesel fuel compliant with Euro IV emission norms was purchased from a nearby petrol filling station. The PDS kerosene was purchased from a nearby Government licensed ration dealer. All the solvents used in the study such as $n$-heptane, cyclohexane, and aniline, etc. were HPLC grade and purchased from Merck Specialties Pvt. Ltd. (Mumbai, India). The analytical standards such as o-xylene, 1-methylnaphthalene and phenanthrene were purchased from Sigma Aldrich Pvt. Ltd (Bangalore, India).

\subsection{Samples}

The samples were prepared by mixing the varying amount of PDS kerosene in the diesel fuel separately in a $250 \mathrm{~mL}$ glass bottle (Duran, Germany) having a screw cap, PTFE coated silicone seal and a pouring ring. For simulating the adulteration scenario, PDS kerosene were blended to the diesel in varying concentrations i.e. $5 \%, 10 \%, 15 \%, 20 \%$, $30 \%$ and $40 \%(\mathrm{v} / \mathrm{v})$. Afterwards, the glass bottles were closed tightly, and the contents were mixed thoroughly through shaking. To prevent the losses due to evaporation, the resulting samples were stored at $4{ }^{\circ} \mathrm{C}$ in a refrigerator.

\subsection{Instrumentation}

The GC analysis comprised the n-paraffin distribution in the samples and carried out as per the standard test methods UOP915 and ASTM D6730 through a model CP3800 gas chromatograph equipped with flame ionization detector (Varian Instruments Pvt. Ltd., Mumbai, India). A Varian CPSIL PONA CB capillary column having $100 \mathrm{~m}$ length, $0.25 \mathrm{~mm}$ i.d. and $0.5 \mu \mathrm{m}$ film thickness was used in the $\mathrm{GC}$ analysis. The GC oven was programmed from $35^{\circ} \mathrm{C}$ (hold for $15 \mathrm{~min}$ ) to $60^{\circ} \mathrm{C}$ (hold for $20 \mathrm{~min}$ ) at the rate of $1{ }^{\circ} \mathrm{C} \mathrm{min}-1$ and then to a final temperature of $200^{\circ} \mathrm{C}$ (hold for $70 \mathrm{~min}$ ) at the rate of $2{ }^{\circ} \mathrm{C} \mathrm{min}{ }^{-1}$. Helium at a pressure of 59 psi was used as a carrier gas, and the GC run was carried out under constant pressure mode. A splitless inlet liner with single taper and quartz wool was used, and all the samples were analyzed in the splitless mode at an injector temperature of $400^{\circ} \mathrm{C}$ with the detector temperature being maintained at $420^{\circ} \mathrm{C}$. An injection volume of $1 \mu \mathrm{L}$ was used throughout the study for all samples using a 5 $\mu \mathrm{L}$ Hamilton micro-syringe. The results were calculated through the Galaxie software of the detailed hydrocarbon analyzer system.

The HPLC analysis was carried out with an HPLC system (model: Prominence, Shimadzu Analytical (India) Pvt. Ltd, New Delhi) equipped with a refractive index detector. All the samples were analyzed for non-aromatics, mono-, diand tri+-aromatic content as per standard test method IP391/ASTM D6591. An Agilent ZORBAX NH $\mathrm{N}_{2} \mathrm{HPLC}$ column (Agilent Technologies Inc., USA) with $250 \mathrm{~mm}$ length, $4.6 \mathrm{~mm}$ i.d. and $5 \mu \mathrm{m}$ particle size along with an Agilent ZORBAX $\mathrm{NH}_{2}$ guard column $(12.5 \mathrm{~mm}$ length $\times 4.6 \mathrm{~mm}$ i.d. $\times 5 \mu \mathrm{m}$ particle size) was used. $n$-Heptane was used as mobile phase under isocratic elution condition at a flow rate of $1 \mathrm{ml} \mathrm{min}^{-1}$. The analysis temperature was maintained at $30^{\circ} \mathrm{C}$, and $20 \mu \mathrm{L}$ of the sample was injected through a model SIL-20A HT autosampler. The HRMS analysis was performed through a double focusing magnetic sector mass spectrometer (model: Auto concept; Mass Spectrometry Instruments Ltd. Dewsbury, U.K.). $1 \mu \mathrm{L}$ sample was injected through a $5 \mu \mathrm{L}$ Hamilton micro-syringe into an All Glass Heated Inlet System. The injector port, oven, and interface of this inlet were maintained at $250^{\circ} \mathrm{C}$, $275^{\circ} \mathrm{C}$, and $300^{\circ} \mathrm{C}$ respectively. An electron ionization source was used for ionizing the gaseous phase sample under positive ion mode $(70 \mathrm{eV})$, and the ion source was maintained at $250{ }^{\circ} \mathrm{C}$. The magnet scanning of $10 \mathrm{~s}$ per decade was used within the mass range of $m / z 45-500$. Perfluorokerosene was used as a reference for the accurate mass measurement, and a resolution of 10,000 was used for recording the mass spectra for each sample. For each complete run, a minimum of 35 scans were acquired, and the average value for exact individual masses $(\mathrm{m} / \mathrm{z})$ was obtained from the continuous high-resolution scans. The high-resolution masses were processed further through HC22 software (Petromass, USA). Analyses with all the techniques were carried out in triplicate, and only the average results have been presented. The density measurements for all the samples were carried out with a density meter (model: DMA4500M; Anton Paar India Pvt. Ltd, Gurgaon, India) using the standard test method ASTM D4052. The kinematic viscosity of samples was measured with an automatic viscometer (model: Stabinger 3001; Anton Paar India Pvt. Ltd, Gurgaon, India) using the standard test method ASTM D7042. Atmospheric distillation of all the test samples was carried out through an ISL Micro distillation unit (model: PMD 100; PAC, Mumbai, India) using ASTM D86. The total sulfur content was determined by X-ray fluorescence (XRF) analyzer (model: LabX3500SCL; Oxford Instruments, Hitachi, Mumbai, India) using method ASTM D4294. The aniline point of all the samples was determined as per the standard test procedure ASTM D611. 


\section{Results and discussion}

In view of the associated challenges in the analysis of petroleum distillates above gasoline, the scope of development of the new method is limited. Diesel fuel is a part of middle distillates and has overlapping hydrocarbons with kerosene and aviation fuel. The determination of adulteration in diesel fuel requires a sound understanding of its structural complexity and prevailing regulatory specifications. In this study analysis of BSIV diesel contaminated with PDS kerosene was carried out with prominent standard tests. They included density, viscosity, atmospheric distillation, aniline point, cetane index and sulfur content. The results from these tests were analyzed along with those obtained with GC, HPLC and HRMS.

\subsection{Physicochemical analysis}

\subsubsection{Density}

The regulatory specification for automotive diesel fuel as per IS 1460 stipulates its density to remain within $820-845 \mathrm{~kg} / \mathrm{m}^{3}$ at $15{ }^{\circ} \mathrm{C}$ which is determined by ASTM D4052 through a digital density meter. Measurement of density as per ASTM D1298 through hydrometer method is an important measure of fuel quality since its availability at the retail outlets, and its results may be considered as a preliminary indicator of fuel adulteration. Addition of kerosene lowers its density and the same was confirmed through the experiments. As the kerosene contents increased in the diesel samples, a decreasing trend in density was noticed (Table 1). In comparison to the density of unadulterated diesel $\left(830 \mathrm{~kg} / \mathrm{m}^{3}\right)$, a gradual decrease up to $821 \mathrm{~kg} / \mathrm{m}^{3}$ was recorded with the final addition of $40 \%$ kerosene $(\mathrm{v} / \mathrm{v})$. The density of PDS kerosene (adulterant) was measured to be $802 \mathrm{~kg} / \mathrm{m}^{3}$. The steady decline in density indicated the change in the overall density however; all the samples conformed to the regulatory specifications of the automotive diesel indicating that the presence of kerosene cannot be concluded on the basis density measurements. It is important to emphasize that density measurement results can only indicate adulterations if the levels of adulterants are significantly high [23].

\subsubsection{Kinematic viscosity}

The regulatory specifications of kinematic viscosity for automotive diesel fuel shall remain in the range of 2.0-4.5 CSt at $40{ }^{\circ} \mathrm{C}$. ASTM D7042 was followed for the determination of kinematic viscosity, and its value for unadulterated diesel and PDS kerosene was recorded at 2.86 and $1.23 \mathrm{cSt}$ respectively. From the Table 1, a decreasing trend in the Kinematic viscosity across the samples containing increasing kerosene content can be noticed. The decrease is obvious due to the relatively low viscosity of kerosene as compared to diesel. The viscosities decreased from $2.59 \mathrm{cSt}$ (5\% kerosene) to $1.95 \mathrm{cSt}$ ( $40 \%$ kerosene) weakly indicating a mild adulteration with a low-viscosity diluents at $40 \%$ level. The diesel samples are expected not to comply with the specifications if the concentration of kerosene is increased above $40 \%$ in them. Similar to the density profile of the studied samples, it was observed that the viscosity values for all adulterated diesel samples were found to lie within the prescribed range as per IS 1460. In view of this, It may be noted that density and kinematic viscosity being closely related physical properties provide only a very weak sign of diesel adulteration with up to $40 \%$ kerosene.

\subsubsection{Atmospheric distillation}

Atmospheric distillation of the experimental samples was carried out as per ASTM D86. The standard IS 1460 specifies the distillation recovery of diesel at $360^{\circ} \mathrm{C}$ to be minimum $95 \%(\mathrm{v} / \mathrm{v})$. For the diesel and kerosene samples, the boiling range of $145.4{ }^{\circ} \mathrm{C}$ to $369.5^{\circ} \mathrm{C}$ and $155.1^{\circ} \mathrm{C}$ to $249.1{ }^{\circ} \mathrm{C}$ was determined separately. The $95 \%$ recovery for unadulterated diesel was achieved at $360.2^{\circ} \mathrm{C}$, and it was observed that all the samples conformed to the
Table 1 A record of density, Kinematic viscosity, aniline point, total sulfur content and cetane index of diesel fuel samples blended with varying volumes of kerosene

\begin{tabular}{lclllll}
\hline S. no. & $\begin{array}{l}\text { Kerosene in } \\
\text { diesel }[\%(\mathrm{v} / \mathrm{v})]\end{array}$ & $\begin{array}{l}\text { Density at } \\
15^{\circ} \mathrm{C}\left(\mathrm{kg} / \mathrm{m}^{3}\right)\end{array}$ & $\begin{array}{l}\text { Kinematic viscos- } \\
\text { ity at } 40^{\circ} \mathrm{C}(\mathrm{cSt})\end{array}$ & $\begin{array}{l}\text { Aniline } \\
\text { point }\left({ }^{\circ} \mathrm{C}\right)\end{array}$ & $\begin{array}{l}\text { Total sulfur } \\
(\mathrm{ppm})\end{array}$ & Cetane index \\
\hline 1. & 0 & 830 & 2.86 & 80 & 48 & 54.9 \\
2. & 5 & 828 & 2.59 & 78 & 167 & 54.5 \\
3. & 10 & 827 & 2.57 & 74 & 189 & 53.6 \\
4. & 15 & 826 & 2.50 & 70 & 231 & 53.2 \\
5. & 20 & 825 & 2.40 & 71 & 267 & 52.4 \\
6. & 30 & 823 & 2.21 & 68 & 331 & 50.8 \\
7. & 40 & 821 & 1.95 & 63 & 427 & 48.5 \\
8. & 100 & 802 & 1.23 & 55 & 1070 & 43.3 \\
\hline
\end{tabular}


specified criteria. The distillation recovery values were $359.8^{\circ} \mathrm{C}, 359.6{ }^{\circ} \mathrm{C}, 359.2{ }^{\circ} \mathrm{C}, 359.0^{\circ} \mathrm{C}, 357.8^{\circ} \mathrm{C}$ and $349.8^{\circ} \mathrm{C}$ respectively for $5 \%, 10 \%, 15 \%, 20 \%, 30 \%$, and $40 \%$ kerosene blended diesel. It shall be noticed that if kerosene is present in the diesel fuel, it is likely to increase the distillation recovery (at $360^{\circ} \mathrm{C}$ ) of the fuel above its specified value of $95 \%$ which is due to the low-boiling range of kerosene as compared to diesel. In other words, a lower temperature would be required to achieve $95 \%$ distillation recovery for kerosene adulterated diesel samples, as compared to unadulterated diesel. From this viewpoint, it is obvious that a high-boiling adulterant (than diesel) shall decrease the distillation recovery below $95 \%$ to cause the non-compliance with the diesel specifications (IS 1460). Hence, the atmospheric distillation data of diesel fuel has the limitation in the sense that it can easily detect the presence of high boiling substances (adulterants) and not the low-boiling as being studied in the present study.

In India, the specification for superior kerosene oil as per IS 1459 requires the minimum distillation recovery of $20 \%$ at $200{ }^{\circ} \mathrm{C}$ and a final boiling point of less than $300^{\circ} \mathrm{C}$. It was also observed that since the final boiling point of kerosene was $249.1^{\circ} \mathrm{C}$, the distillation recovery of all the adulterated diesel samples at $250^{\circ} \mathrm{C}$ was significantly changed. To this observation, distillation recovery of unadulterated diesel at $250^{\circ} \mathrm{C}$ was determined to be $38.1 \%(\mathrm{v} / \mathrm{v})$ which increased gradually to $39.2 \%, 40.3 \%$, $41.1 \%, 48.6 \%, 50.8 \%$, and significantly to $59.9 \%(\mathrm{v} / \mathrm{v})$ for the samples containing $5 \%, 10 \%, 15 \%, 20 \%, 30 \%$ and $40 \%$ kerosene concentration in diesel respectively. The distillation data is important to the extent where it provides clues to the presence of foreign substances in diesel. The deviation in its profile is measurable and may also be used to yield quantitative information about the adulterant. In the present study, distillation recovery at $250^{\circ} \mathrm{C}$ is considered an important measure of the presence of kerosene in diesel since it showed a proportional increase with the increase in kerosene quantity.

\subsubsection{Aniline point}

The aniline point for all the samples was determined for the purpose of assessing the variations of their aromatic contents. The requirement of aniline point is not stated in the specification (IS 1460) of the diesel fuel. However, it is a strong indicator of the aromatic nature of samples. Its lower value indicates the higher aromatic content of the sample and vice versa. The aniline point was determined with ASTM D611, and its value for diesel and PDS kerosene was recorded at $80^{\circ} \mathrm{C}$ and $55^{\circ} \mathrm{C}$ respectively. From $80^{\circ} \mathrm{C}$, it decreased gradually up to $63^{\circ} \mathrm{C}$ in $40 \%$ kerosene containing sample (Table 1). It is evident from the aniline point value of kerosene that it contains higher aromatic contents as compared to diesel and the same is reflected in the subsequent values mentioned shown in Table 1. Thus aniline point is a strong qualitative indicator of determining the aromatic-rich nature of the sample and therefore helpful in evaluating the presence of kerosene in diesel. This observation was further confirmed by the analysis with HPLC and HRMS based methods.

\subsubsection{Total sulfur}

Determination of total sulfur content of the automotive diesel fuel is considered pertinent to the scenario where PDS kerosene adulteration is suspected. The diesel is allowed to contain a maximum of $50 \mathrm{ppm}$ sulfur as per IS 1460 and required to be analyzed with X-ray fluorescence (XRF) method using ASTM D4294. On the other hand, in India, the maximum sulfur content in kerosene (as per IS 1459) is permissible at $0.25 \mathrm{wt} \%$, i.e. $2500 \mathrm{ppm}$. In the present study, total sulfur content for diesel and kerosene were measured at 48 and $1070 \mathrm{ppm}$ respectively. This huge difference in the sulfur between the two fuels is significant and Table 1 shows the increasing profile of total sulfur content in the experimental samples. It is explicitly shown that the regulatory specifications for total sulfur of diesel exceeded more than thrice by addition of just $5 \%$ of PDS kerosene into it. The increased total sulfur content in diesel samples exclusively indicates the presence of PDS kerosene. Thus, the measurement of sulfur content in the automotive diesel is considered a crucial indicator of its quality.

\subsubsection{Cetane index}

Just as the composition of fuel is an important aspect of its quality control, its ignition property is a direct measure of its composition and considered very important. It is measured in the form of cetane number which is determined through the combustion of fuel under standard test conditions. Cetane index is also used as a substitute of cetane number for diesel fuels, and its values have very close approximation with the cetane number [21]. Hence, in the present study, the samples were subjected to cetane index determination to establish the role of the adulterant (PDS kerosene) in altering the combustion behaviour of the diesel fuel. The cetane index was calculated as the per standard test method ASTM D4737 utilizing the sample's density and distillation range. As per specifications, the cetane index of automotive diesel fuel should be minimum 46, and for the unadulterated diesel sample, it was determined to be 54.9. The cetane index for PDS kerosene was calculated to be 43.3 . The cetane index reduced gradually up to 48.5 in $40 \%$ kerosene containing sample (Table 1). Similar to the density and Kinematic viscosity, 
the $40 \%$ blending of kerosene into the diesel did not result in non-conformance of the cetane index value as per specifications.

It is apparent from the results of the critical physicochemical properties (density, kinematic viscosity, and atmospheric distillation) and cetane index that an inference cannot be drawn on the unambiguous verification of diesel adulteration under the scenario posed in the present study. In contrast, the results of aniline point, atmospheric distillation (recovery at $250^{\circ} \mathrm{C}$ ) and total sulfur content of the samples provided clues for determining the presence of adulterant in the automotive diesel samples. However, the clear distinction between diesel samples being analyzed for adulteration can only be concluded if the molecular level analysis is involved. Hence, to complement and explicitly confirm the findings from physicochemical tests, the GC, HPLC and HRMS characterizations were also carried out and discussed as follows.

\subsection{Chromatographic and mass spectrometric analysis}

Chromatographic analysis of petroleum-based fuels is the most reliable way of obtaining the individual hydrocarbon details or just in the form of hydrocarbon types. Detailed hydrocarbon analysis (DHA) is extensively used in the downstream petroleum industry for the characterization of light distillates up to $225^{\circ} \mathrm{C}$ boiling points. The GCbased applications usually comprise ASTM D5443, D5134, D6729, and D6730 which reveal hydrocarbon group types and individual hydrocarbon components by their structure. It must be noticed that the GC-based methods are the ultimate source of information for individual hydrocarbon components, but the applications are limited to the lighter petroleum distillates, i.e. naphtha and gasoline. Due to the increased complexity of hydrocarbon contents in the middle distillates (i.e. kerosene, aviation fuel and diesel), individual hydrocarbon-level information is not possible through GC.

Therefore, HPLC-based methods play a vital role in determining hydrocarbon type information for middle distillates. Similarly, ASTM D6379 and D6591 are HPLC-based methods used for determining aromatic hydrocarbon types in the middle distillates. These standard methods provide a basis for determining any measurable change in the specified values of the fuel samples and upon adequate interpretation provide valuable clues on the nature of the studied samples. Adulteration measurement is a significant part of quality assurance (QA)/quality control (QC) whose verification relies on the practical understanding of the fuel characteristics and valid interpretations of the analytical results.

\subsubsection{Gas chromatography}

The GC analysis of the studied samples provided chromatograms which were compared for their hydrocarbon fingerprints. Figure 1 shows the comparison of the chromatograms of the unadulterated diesel, $10 \%$ kerosene in diesel, $40 \%$ kerosene in diesel and PDS kerosene as a representative case. This figure gives an overview of the variation in the hydrocarbon profile across each sample, and it was found that the $n$-paraffin pattern provided the distinct appearance to the chromatograms of each sample. The normal paraffin distribution of each prepared sample was calculated with the standard test method UOP915 and ASTM D6730, and their result is presented in Fig. 2. The figures show that the $\mathrm{n}$-paraffin patterns distinctly indicated the dominant hydrocarbon ranges in diesel and PDS kerosene which were between $C_{6}-C_{20}$ and $C_{7}-C_{16}$ respectively.

The chromatograms also show a higher concentration of $n-C_{15}$ and $n-C_{16}$ (3.68\% and $3.52 \%$ respectively) in the diesel, whereas, $\mathrm{n}-\mathrm{C}_{10}, \mathrm{n}-\mathrm{C}_{11}$ and $\mathrm{n}-\mathrm{C}_{12}$ were dominated $(4.30 \%, 3.96 \%$, and $4.46 \%$ respectively) in the kerosene. Accordingly, in the diesel samples containing kerosene, there was an increase in the $n$-paraffin region $\left(n-C_{10}\right.$ to $n-C_{12}$ ) estimated through the chromatograms. The increase was proportional to the volume of adulterant and considered a marker for the presence of kerosene in the diesel samples (Fig. 2). The amount of $\mathrm{n}-\mathrm{C}_{10}, \mathrm{n}-\mathrm{C}_{11}$ and $n-C_{12}$ increased noticeably with the increase in the kerosene concentration, and it also resulted in the gradual decrease in the $n-C_{15}$ to $n-C_{20}$ signals in the chromatograms of kerosene containing diesel samples (Fig. 2). The increase in $\mathrm{n}-\mathrm{C}_{10}, \mathrm{n}-\mathrm{C}_{11}$, and $\mathrm{n}-\mathrm{C}_{12}$ were recorded from $1.69 \%, 1.54 \%$, and $1.96 \%$ in the unadulterated diesel to $2.93 \%, 2.76 \%$, and $3.14 \%$ respectively in the $40 \%$ kerosene adulterated sample.

\subsubsection{High-performance liquid chromatography}

HPLC methods are widely used for determining the aromatic hydrocarbon types in middle distillates. Limitations of GC-based methods for petroleum distillates above gasoline have necessitated the HPLC-based methods for the verification of hydrocarbon types in middle distillates. In this study, the aromatic hydrocarbon types of unadulterated and adulterated diesel fuel samples were analyzed with normal phase HPLC analysis as per ASTM D6591/IP391. A typical elution order of saturates, mono-aromatics, di-aromatics and tri+-aromatics in diesel, kerosene, and kerosene $10 \%$ and $40 \%$ ) in diesel is shown in Fig. 3a. The quantitative distribution of these hydrocarbon types is presented in Table 2. Also, the individual peak areas of mono-, di-, and trit-aromatics have been compared to determine their 

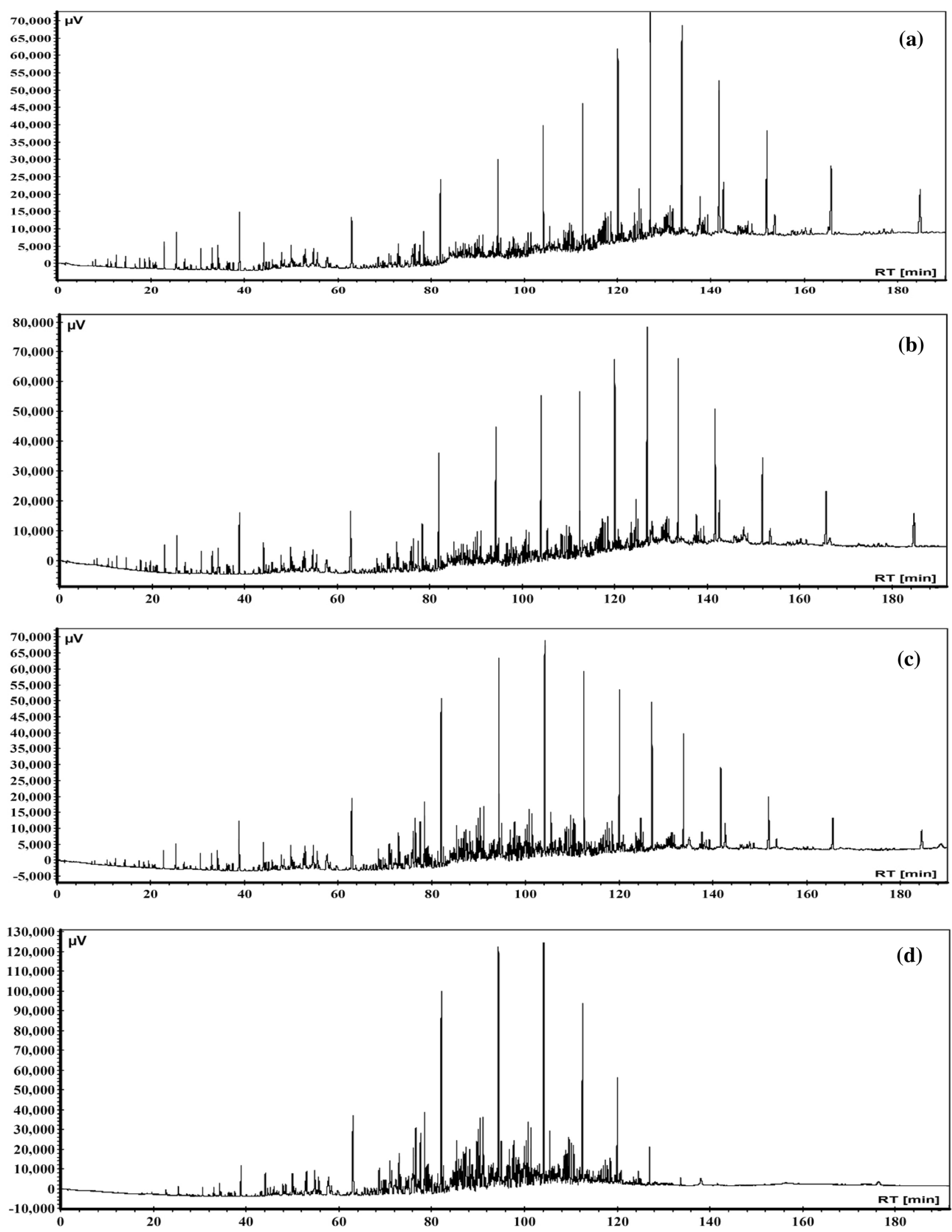

Fig. 1 Gas chromatograms of the commercial diesel and kerosene samples $(\mathbf{a}, \mathbf{d})$ along with the blended samples of diesel containing $10 \%$ and $40 \%$ kerosene $(b, c)$ 
Fig. 2 Distribution of $n$-paraffins in the commercial diesel, kerosene and $40 \%$ kerosene in diesel determined through GC

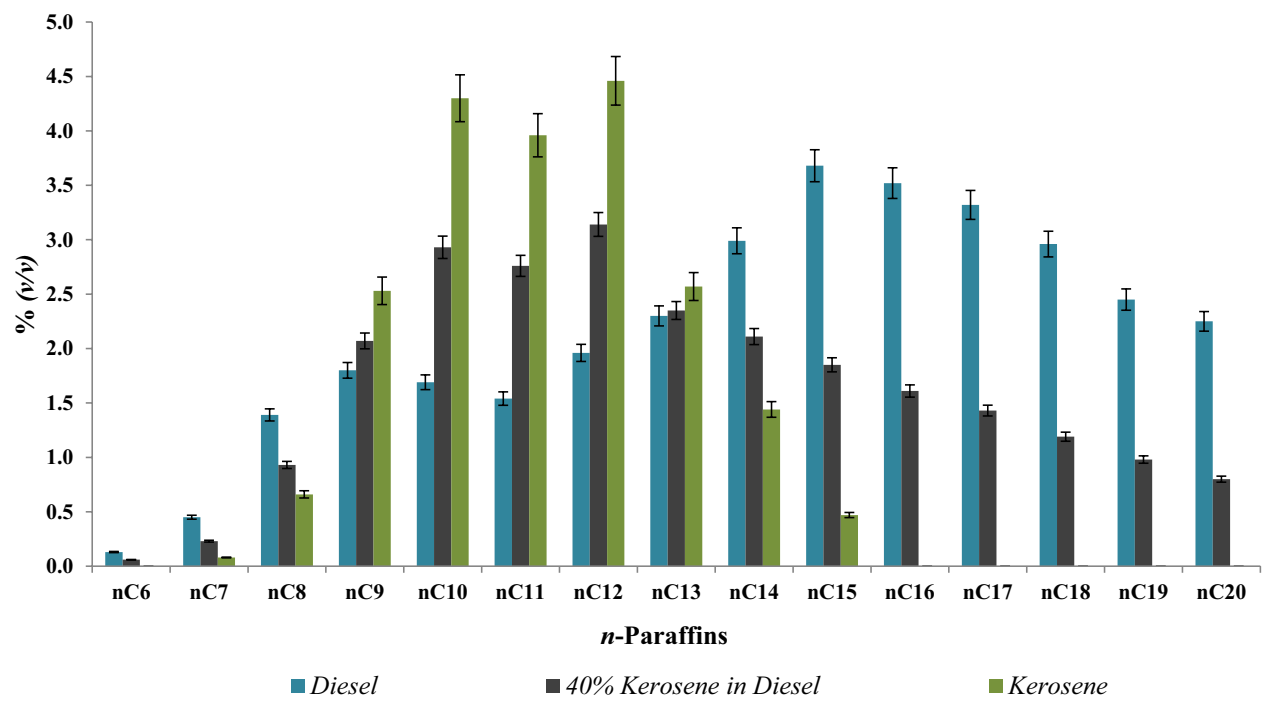

variation trend. In the kerosene, tri+-aromatics were not observed at all whereas mono- and di-aromatics were significantly higher as compared to the diesel. A proportional increase in the mono- and di-aromatics was recorded in the adulterated diesel samples as shown in Fig. $3 \mathrm{~b}$ for two representative samples (10\% and $40 \%$ kerosene in diesel).

Table 2 shows a decreasing trend of the saturated hydrocarbons measured in the experimental samples (diesel containing increasing kerosene content) with the help of the HPLC method. Conversely, with the increasing kerosene content in diesel samples, the aromatics hydrocarbons were increased. The total saturates (or non-aromatics) were estimated at $88.5 \%$ and $83.2 \%$ respectively in diesel and kerosene samples whereas the total aromatics were $11.5 \%$ and $16.8 \%$ respectively. Upon increasing the kerosene content in diesel from 5 to $40 \%$, a decrease in the total saturates and an increase in the total aromatics was observed. In this way, the total saturates decreased from $88.5 \%$ to $87.5 \%, 86.1 \%, 85.0 \%$ and $84.5 \%$ respectively in diesel and diesel samples containing $10 \%, 20 \%, 30 \%$ and $40 \%$ kerosene. Total aromatics, however, increased from $11.5 \%$ in diesel to $12.5 \%$, $13.9 \%, 15.0 \%$ and $15.5 \%$ in $10 \%, 20 \%, 30 \%$ and $40 \%$ kerosene containing diesel samples. It must be noted that the increase was significant for mono-aromatics only which increased from $12.0 \%$ to $13.3 \%, 14.4 \%$, and $14.9 \%$ respectively in the same samples. It is important to mention that kerosene being low-boiling than diesel was rich in mono-aromatic hydrocarbons only. The concentration of poly-aromatics which were estimated at $0.8 \%$ (di-aromatics only) in kerosene was slightly above at $0.5 \%$ (di + tri+-aromatics) in diesel.

Fig. 3 HPLC chromatograms depicting a overall hydrocarbons, and b aromatic hydrocarbons distribution in kerosene blended diesel samples 
Table 2 A comparison of hydrocarbon types in the studied samples determined through HRMS and HPLC with the standard deviation

\begin{tabular}{|c|c|c|c|c|}
\hline Sample & Hydrocarbon class & $\begin{array}{l}\text { HRMS method } \\
\text { (HC22) }\end{array}$ & $\begin{array}{l}\text { HPLC method } \\
\text { (IP391) }\end{array}$ & $\mathrm{t}$ value \\
\hline \multirow[t]{5}{*}{ Diesel } & Saturates & $88.9 \pm 0.1$ & $88.5 \pm 0.7$ & 1.13 \\
\hline & Mono-aromatics & $10.7 \pm 0.1$ & $11.0 \pm 0.6$ & -0.92 \\
\hline & Di-aromatics & $0.3 \pm 0.0$ & $0.4 \pm 0.0$ & 0.00 \\
\hline & Tri+-aromatics & $0.1 \pm 0.0$ & $0.1 \pm 0.0$ & 0.00 \\
\hline & Total aromatics & $11.1 \pm 0.1$ & $11.5 \pm 0.7$ & -1.01 \\
\hline \multirow[t]{5}{*}{$5 \%$ kerosene in diesel } & Saturates & $88.3 \pm 0.3$ & $87.4 \pm 0.8$ & 1.78 \\
\hline & Mono-aromatics & $11.3 \pm 0.3$ & $12.1 \pm 0.8$ & -1.57 \\
\hline & Di-aromatics & $0.3 \pm 0.0$ & $0.4 \pm 0.0$ & 0.0 \\
\hline & Tri+-aromatics & $0.1 \pm 0.0$ & $0.1 \pm 0.0$ & 0.0 \\
\hline & Total aromatics & $11.7 \pm 0.3$ & $12.6 \pm 0.8$ & -1.78 \\
\hline \multirow[t]{5}{*}{$10 \%$ kerosene in diesel } & Saturates & $86.5 \pm 0.4$ & $87.5 \pm 0.6$ & -2.31 \\
\hline & Mono-aromatics & $12.9 \pm 0.3$ & $12.0 \pm 0.6$ & 2.02 \\
\hline & Di-aromatics & $0.5 \pm 0.1$ & $0.4 \pm 0.0$ & 4.00 \\
\hline & Tri+-aromatics & $0.1 \pm 0.0$ & $0.1 \pm 0.0$ & 0.00 \\
\hline & Total aromatics & $13.5 \pm 0.4$ & $12.5 \pm 0.6$ & 2.31 \\
\hline \multirow[t]{5}{*}{$20 \%$ kerosene in diesel } & Saturates & $86.3 \pm 0.3$ & $86.1 \pm 0.1$ & 1.34 \\
\hline & Mono-aromatics & $13.2 \pm 0.3$ & $13.3 \pm 0.1$ & -0.38 \\
\hline & Di-aromatics & $0.4 \pm 0.0$ & $0.5 \pm 0.0$ & 0.0 \\
\hline & Tri+-aromatics & $0.1 \pm 0.0$ & $0.1 \pm 0.0$ & 0.0 \\
\hline & Total aromatics & $13.7 \pm 0.3$ & $13.9 \pm 0.1$ & -0.78 \\
\hline \multirow[t]{5}{*}{$30 \%$ kerosene in diesel } & Saturates & $85.4 \pm 0.8$ & $85.0 \pm 0.1$ & 0.99 \\
\hline & Mono-aromatics & $14.0 \pm 0.8$ & $14.4 \pm 0.1$ & -1.27 \\
\hline & Di-aromatics & $0.5 \pm 0.0$ & $0.5 \pm 0.0$ & 0.0 \\
\hline & Tri+-aromatics & $0.1 \pm 0.0$ & $0.1 \pm 0.0$ & 0.0 \\
\hline & Total aromatics & $14.6 \pm 0.8$ & $15.0 \pm 0.1$ & -0.99 \\
\hline \multirow[t]{5}{*}{$40 \%$ kerosene in diesel } & Saturates & $85.1 \pm 0.3$ & $84.5 \pm 0.3$ & 2.50 \\
\hline & Mono-aromatics & $14.3 \pm 0.4$ & $14.9 \pm 0.3$ & -1.90 \\
\hline & Di-aromatics & $0.5 \pm 0.1$ & $0.5 \pm 0.1$ & 0.0 \\
\hline & Tri+-aromatics & $0.1 \pm 0.0$ & $0.1 \pm 0.0$ & 0.0 \\
\hline & Total aromatics & $14.9 \pm 0.4$ & $15.5 \pm 0.3$ & -2.13 \\
\hline \multirow[t]{5}{*}{ Kerosene } & Saturates & $83.7 \pm 0.8$ & $83.2 \pm 0.1$ & 1.14 \\
\hline & Mono-aromatics & $15.5 \pm 0.7$ & $16.0 \pm 0.2$ & -1.21 \\
\hline & Di-aromatics & $0.8 \pm 0.1$ & $0.8 \pm 0.1$ & 0.0 \\
\hline & Tri+-aromatics & 0.0 & 0.0 & 0.0 \\
\hline & Total aromatics & $16.3 \pm 0.8$ & $16.8 \pm 0.1$ & -1.07 \\
\hline
\end{tabular}

\subsubsection{High-resolution mass spectrometry}

Mass spectrometry is a powerful technique utilized for gathering details about hydrocarbon types of petroleum fuels based on the empirical molecular composition of the hydrocarbons. The HC22 analysis (based on HRMS) of the samples were carried out which revealed very close similarity in the concentration of all hydrocarbon types which were also determined with ASTM D6591/IP391. A comparison of the same is given in Table 2 and illustrated in Fig. 4, though, much detailed $\mathrm{HC} 22$ results have been provided in Table 3. The important aspect of analysis through HC22 is the comprehensive information on structurally diverse hydrocarbons and their quantities. It is a program that utilizes important and unique exact masses of the hydrocarbons from different classes. The PIONA (Paraffins, IsoParaffins, Olefins, Naphthenes and Aromatics) information is provided into 22 different types of hydrocarbons detailing saturates, aromatics, sulfur-containing and nitrogencontaining hydrocarbons. The concentrations of paraffins and monocycloparaffins were almost in the reverse order in diesel (39.4\% and $25.1 \%$ ) as compared to kerosene (27.4\% and $38.3 \%$ ). Hence, the effect of increased kerosene concentration in diesel had a relative impact on the overall concentration of these two classes. Among the monoaromatics, alkylbenzenes were prominent and estimated 
Fig. 4 Determination of saturated and aromatic hydrocarbons in diesel samples containing varying volume of kerosene through highresolution mass spectrometry and HPLC

Table 3 Determination of different hydrocarbon types in the diesel fuel samples adulterated with kerosene through high-resolution mass spectrometry aided with $\mathrm{HC} 22$ data analysis

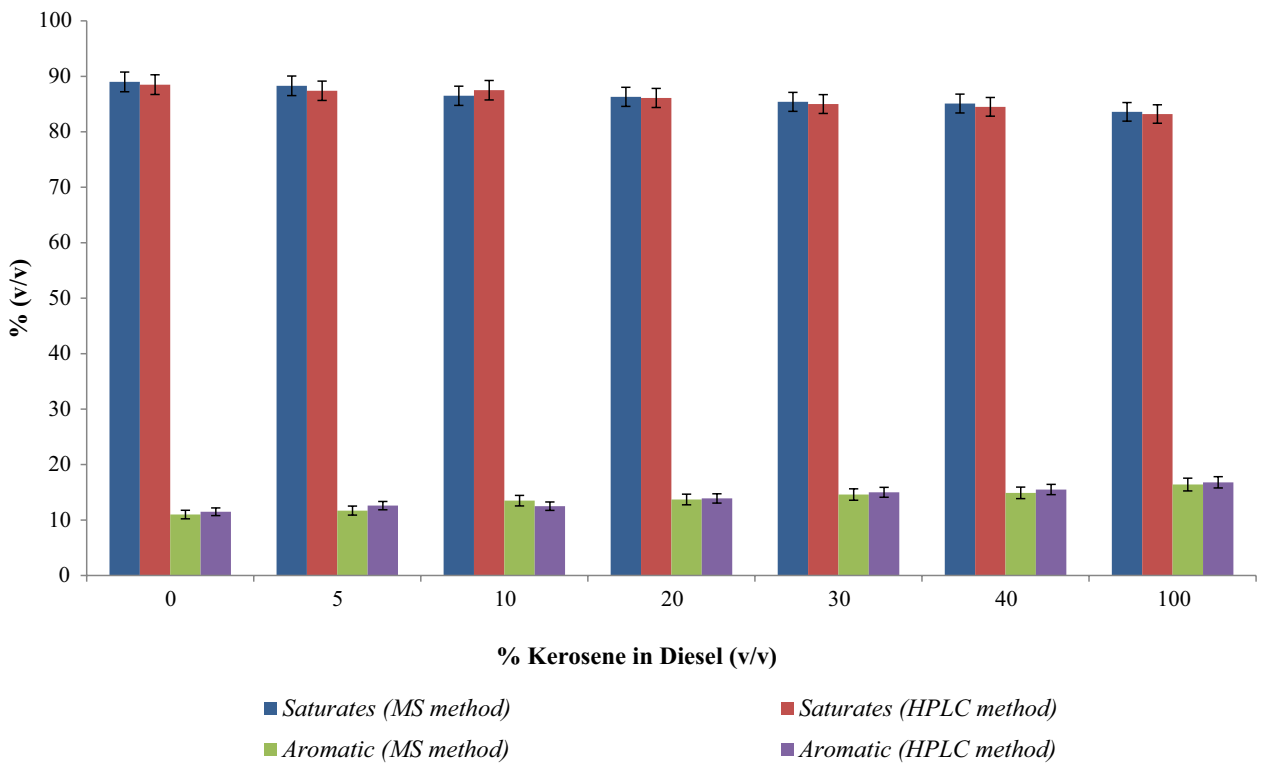

\begin{tabular}{|c|c|c|c|c|c|c|c|c|}
\hline \multirow[t]{3}{*}{ Hydrocarbon classes } & & \multicolumn{7}{|l|}{$\% \mathrm{v} / \mathrm{v}$} \\
\hline & & \multirow[t]{2}{*}{ Diesel } & \multicolumn{5}{|c|}{ Kerosene in diesel } & \multirow[t]{2}{*}{ Kerosen€ } \\
\hline & & & $5 \%$ & $10 \%$ & $20 \%$ & $30 \%$ & $40 \%$ & \\
\hline \multicolumn{9}{|l|}{ Saturates } \\
\hline Paraffins & $\mathrm{C}_{n} \mathrm{H}_{2 n+2}$ & 39.4 & 38.4 & 37.9 & 37.2 & 36.4 & 36.7 & 27.4 \\
\hline Monocycloparaffins & $\mathrm{C}_{\mathrm{n}} \mathrm{H}_{2 \mathrm{n}}$ & 25.0 & 26.9 & 27.0 & 27.9 & 27.2 & 29.2 & 38.4 \\
\hline Dicycloparaffinss & $\mathrm{C}_{\mathrm{n}} \mathrm{H}_{2 \mathrm{n}-2}$ & 17.7 & 16.8 & 15.0 & 14.7 & 16.3 & 15.9 & 16.1 \\
\hline Tricycloparaffins & $\mathrm{C}_{\mathrm{n}} \mathrm{H}_{2 \mathrm{n}-4}$ & 6.8 & 6.2 & 6.6 & 6.5 & 5.5 & 3.3 & 1.8 \\
\hline Tetracycloparaffins & $\mathrm{C}_{\mathrm{n}} \mathrm{H}_{2 \mathrm{n}-6}$ & 0.0 & 0.0 & 0.0 & 0.0 & 0.0 & 0.0 & 0.0 \\
\hline Pentacycloparaffins & $\mathrm{C}_{\mathrm{n}} \mathrm{H}_{2 \mathrm{n}-8}$ & 0.0 & 0.0 & 0.0 & 0.0 & 0.0 & 0.0 & 0.0 \\
\hline Hexacycloparaffins & $\mathrm{C}_{\mathrm{n}} \mathrm{H}_{2 \mathrm{n}-10}$ & 0.0 & 0.0 & 0.0 & 0.0 & 0.0 & 0.0 & 0.0 \\
\hline Heptacycloparaffins & $\mathrm{C}_{\mathrm{n}} \mathrm{H}_{2 \mathrm{n}-12}$ & 0.0 & 0.0 & 0.0 & 0.0 & 0.0 & 0.0 & 0.0 \\
\hline Total saturates & & 88.9 & 88.3 & 86.5 & 86.3 & 85.4 & 85.1 & 83.7 \\
\hline \multicolumn{9}{|l|}{ Aromatics } \\
\hline \multicolumn{9}{|l|}{ Mono-aromatics } \\
\hline Alkylbenzenes & $\mathrm{C}_{\mathrm{n}} \mathrm{H}_{2 \mathrm{n}-6}$ & 6.6 & 7.3 & 10.5 & 10.1 & 10.4 & 12.0 & 12.5 \\
\hline Benzocycloparaffins & $\mathrm{C}_{\mathrm{n}} \mathrm{H}_{2 \mathrm{n}-8}$ & 4.1 & 3.8 & 2.4 & 3.0 & 3.6 & 2.3 & 3.0 \\
\hline Benzodicycloparaffins & $\mathrm{C}_{\mathrm{n}} \mathrm{H}_{2 \mathrm{n}-10}$ & 0.0 & 0.2 & 0.0 & 0.1 & 0.0 & 0.0 & 0.0 \\
\hline Total monoaromatics & & 10.7 & 11.3 & 12.9 & 13.2 & 14.0 & 14.3 & 15.5 \\
\hline \multicolumn{9}{|l|}{ Di-aromatics } \\
\hline Naphthalenes & $\mathrm{C}_{\mathrm{n}} \mathrm{H}_{2 \mathrm{n}-12}$ & 0.3 & 0.3 & 0.5 & 0.4 & 0.5 & 0.5 & 0.8 \\
\hline Acenaphthenes and biphenyls & $\mathrm{C}_{\mathrm{n}} \mathrm{H}_{2 \mathrm{n}-14}$ & 0.0 & 0.0 & 0.0 & 0.0 & 0.0 & 0.0 & 0.0 \\
\hline Acenaphthylenes and fluorenes & $\mathrm{C}_{\mathrm{n}} \mathrm{H}_{2 \mathrm{n}-16}$ & 0.0 & 0.0 & 0.0 & 0.0 & 0.0 & 0.0 & 0.0 \\
\hline Total di-aromatics & & 0.3 & 0.3 & 0.5 & 0.4 & 0.5 & 0.5 & 0.8 \\
\hline \multicolumn{9}{|l|}{ Tri+-aromatics } \\
\hline Phenanthrenes & $\mathrm{C}_{\mathrm{n}} \mathrm{H}_{2 \mathrm{n}-18}$ & 0.1 & 0.1 & 0.1 & 0.1 & 0.1 & 0.1 & 0.0 \\
\hline Pyrenes & $\mathrm{C}_{n} \mathrm{H}_{2 \mathrm{n}-22}$ & 0.0 & 0.0 & 0.0 & 0.0 & 0.0 & 0.0 & 0.0 \\
\hline Total tri+-aromatics & & 0.1 & 0.1 & 0.1 & 0.1 & 0.1 & 0.1 & 0.0 \\
\hline Total aromatics & & 11.1 & 11.7 & 13.5 & 13.7 & 14.6 & 14.9 & 16.3 \\
\hline
\end{tabular}


to be almost double in kerosene $(12.5 \%)$ as compared to diesel (6.7\%). The concentration of dicycloparaffins (saturates) and benzocycloparaffins (aromatics) was approximately similar in both the cases (Table 3).

\subsection{Analytical figures of merit}

The analyses were performed in triplicate, and the resultant values are given as an average of the individual values. The relative standard deviation (RSD) of saturates measurement through HPLC was estimated to lie within $0.10-0.86$ whereas; it was in the range of $0.13-0.95$ with the HRMS-based HC22 method. The RSD for the determination of total aromatics through HPLC and HC22 methods were in the range of $0.34-5.97$ and $0.53-5.55$ respectively. The RSD for individual $n$-paraffins estimated through GC was in the range of $0.65-10.42$. The results of hydrocarbon type quantification obtained separately with HPLC, and HC22 methods were treated statistically for Student's $t$-test. An excellent correlation between the values was obtained with HPLC, and $\mathrm{HC} 22$ methods for the results of saturates, mono-, di- and tri+-aromatics in diesel, kerosene and their blends as shown in Table 2. The Student's $t$-test was used to evaluate the mean values obtained from two different methods, i.e. HPLC and HC22 analysis (Table 2). With these analyses, the calculated probability $P<0.05$ was considered significant statistically with the significance level of 95\% ( $a=0.05)$ between the mean values obtained with HC22 and HPLC methods except for di-aromatics in the $10 \%$ kerosene-diesel blend.

\section{Conclusion}

The present study was focused on the verification of automotive diesel fuel adulteration with PDS kerosene, which is very likely under India's prevailing pricing policy of petroleum-based fuels. The study utilized different analytical methods ranging from physicochemical tests to chromatography and mass spectrometry in monitoring the regulatory specifications of the diesel fuel under the presented adulteration scenario. Through the results of density, kinematic viscosity, distillation and cetane index, it was noticed that they were very well within the regulatory specifications of diesel fuel even with the $40 \%$ adulteration of PDS kerosene in it. On the contrary, the total sulfur has provided strong evidence of the increasing sulfur content in the diesel samples containing increasing kerosene concentrations. Out of the purview of regulatory specification for diesel fuel, aniline point and the atmospheric distillation (recovery at $250^{\circ} \mathrm{C}$ ) have provided strong evidence for the presence of kerosene in diesel. The assumptions deduced from aniline point measurement were further confirmed with the HPLC-based and HC22 analysis for detailed hydrocarbon type information of the samples. It also emerges out broadly from the outcomes of the present study that monitoring adulteration of the automotive diesel fuel with PDS kerosene is difficult especially up to its $40 \%$ level. In particular, the results of GC, HPLC, and HRMS were highly conclusive in the determination of molecular level information of the studied samples and exhibited excellent correlation with the other properties. In the developing countries, the application of the presented method is considered important in determining the presence of PDS kerosene in the diesel fuel.

Acknowledgements The authors acknowledge the financial support received from the Council of Scientific and Industrial Research (CSIR), New Delhi, India under the project OLP-522219. The authors are profoundly thankful to Dr. Anjan Ray, Director, CSIR-Indian Institute of Petroleum for the encouragement and valuable suggestions received during this study. All the scientists and staff of Analytical Science Division and especially from Advanced Crude oil Research Centre, CSIR-IIP are greatly acknowledged for their valuable analytical support.

\section{Compliance with ethical standards}

Conflict of interest The authors declare that they have no conflicts of interest.

\section{References}

1. Chaudhuri UR (2011) Fundamentals of petroleum and petrochemical engineering. CRC Press, Boca Raton

2. Vempatapu BP, Kanaujia PK (2017) Monitoring petroleum fuel adulteration: a review of analytical methods. Trends Anal Chem 92:1-11

3. Kim Y, Kim NY, Park SY, Lee D, Lee JH (2013) Classification and individualization of used engine oils using elemental composition and discriminant analysis. Forensic Sci Int 230:58-67

4. Tharby $R$ (2002) Catching gasoline and diesel adulteration. South Asia urban air quality management briefing note number 7. World Bank, Washington

5. Moreira LS, Avila LA, Azevedo DA (2003) Automotive gasoline quality analysis by gas chromatography: study of adulteration. Chromatographia 58:501-505

6. Tan KM, Barman I, Dingari NC, Singh G, Chia TF, Tok WL (2013) Toward the development of raman spectroscopy as a non perturbative online monitoring tool for gasoline adulteration. Anal Chem 85:1846-1851

7. Flumignan DL, Anaia GC, Ferreira FDO, Tininis AG, de Oliveira JE (2007) Screening brazilian automotive gasoline quality through quantification of saturated hydrocarbons and anhydrous ethanol by gas chromatography and exploratory data analysis. Chromatographia 65:617-623

8. Gomes GS, Santos BCDB, de Oliveira JE (2009) Screening brazilian commercial gasoline quality by ASTM D6733 GC and pattern-recognition multivariate SIMCA chemometric analysis. Chromatographia 69:719-727

9. Hatanaka RR, Flumignan DL, de Oliveira JE (2009) GC fingerprints coupled to pattern-recognition multivariate SIMCA 
chemometric analysis for Brazilian gasoline quality studies. Chromatographia 70:1135-1142

10. Kulathunga DR, Mahanama KRR (2013) Fingerprinting diesel and petrol fuels for adulteration in Sri Lanka. J Natl Sci Found Sri Lanka 41:287-292

11. Fuel adulteration (2015) NGT orders inspection of petrol pumps. https://timesofindia.indiatimes.com/home/environment/Fueladulteration-NGT-ordersinspection-of-petrol-pumps/articlesho w/50270572.cms. Accessed 21 Dec 2015

12. Supreme Court asks government to check rampant adulteration at fuel pumps. http://indianexpress.com/article/india/india -news-india/take-steps-to-check-rampant-adulteration-at-fuelpumps-sc-to-govt-2998446/. Accessed 27 Aug 2016

13. None of 17 accredited labs have facility to check fuel adulteration. http://indianexpress.com/article/india/india-newsindia/facility-to-check-fuel-adulteration-petroleum-ministryngt-3010968/. Accessed 3 Sept 2016

14. Singh D, Singal SK, Garg MO, Maiti P, Mishra S, Ghosh PK (2015) Transient performance and emission characteristics of a heavy-duty diesel engine fuelled with microalga Chlorella variabilis and Jatropha curcas biodiesels. Energy Convers Manage 106:892-900

15. Vempatapu BP, Kumar J, Singh D, Kanaujia PK (2018) Determination of polycyclic aromatic hydrocarbons in biodiesel exhaust from Jatropha curcas and Chlorella variabilis by gas chromatography with flame ionization detection. Anal Lett 51:1304-1309

16. Cunha DA, Montes LF, Castro EVR, Barbosa LL (2016) NMR in the time domain: a new methodology to detect adulteration of diesel oil with kerosene. Fuel 166:79-85

17. Lee J, Balakrishnan S, Cho J, Jeon SH, Kim JM (2011) Detection of adulterated gasoline using colorimetric organic microfibers. J Mater Chem 21:2648-2655

18. Shimamoto GG, Bianchessi LF, Tubino M (2017) Alternative method to quantify biodiesel and vegetable oil in diesel-biodiesel blends through 1H NMR spectroscopy. Talanta 168:121-125
19. Goodman MR, Kaley EA, Finney EE (2016) Forensic analysis of biodiesel. Forensic Sci Int 263:10-26

20. Speight JG (2006) The chemistry and technology of petroleum. CRC Press, Boca Raton

21. Speight JG (2001) Handbook of petroleum product analysis. Wiley, New Jersey

22. More BP, Malve MK, Toche RB, Shinde DB (2012) Analysis of adulterant kerosene in diesel by kinematic viscosity measurement. Int J Pharm Biol Sci 2:256-261

23. Yadav SR, Murthy KV, Mishra D, Baral B (2005) Estimation of petrol and diesel adulteration with kerosene and assessment of usefulness of selected automobile fuel quality test parameters. Int J Environ Sci Technol 1:253-255

24. Akiyama K (2001) Analysis of aromatic hydrocarbon types in diesel fuels by capillary multi-dimensional gas chromatography. Chromatographia 53:340-344

25. Briker Y, Ring Z, lacchelli A, McLean N, Rahimi PM, Fairbridge $C$ (2001) Diesel fuel analysis by GC-FIMS: aromatics, n-paraffins and isoparaffins. Energy Fuels 15:23-37

26. Haddad R, Regiani T, Klitzke CF, Sanvido GB, Corilo YE, Augusti DV, Pasa VMD, Pereira RCC, Romao W, Vaz BG, Augusti R, Eberlin MN (2012) Gasoline, kerosene, and diesel fingerprinting via polar markers. Energy Fuels 26:3542-3547

27. Patra D, Mishra AK (2000) Effect of sample geometry on synchronous fluorimetric analysis of petrol, diesel, kerosene and their mixtures at higher concentration. Analyst 125:1383-1386

28. Teeter RM (1985) High resolution mass spectrometry for type analysis of complex hydrocarbon mixtures. Mass Spectrom Rev 4:123-143

Publisher's Note Springer Nature remains neutral with regard to jurisdictional claims in published maps and institutional affiliations. 